\title{
Induction of dystrophin localization in cultured Xenopus muscle cells by
}

\section{latex beads}

\author{
H. BENJAMIN PENG* and QIMING CHEN
}

Department of Cell Biology and Anatomy, and the Curriculum in Neurobiology, University of North Carolina at Chapel Hill, CB 7090, 108 Taylor Hall, Chapel Hill, NC 27599, USA

*Author for correspondence

\section{Summary}

The distribution of dystrophin in Xenopus myotomal muscle cells was examined in conventional and confocal immunofluorescence microscopy. By labeling dissociated single muscle fibers with a monoclonal or a polyclonal antibody against dystrophin, we found that dystrophin is ten times more concentrated at the myotendinous junction (MTJ) than at the extrajunctional sarcolemma. At the MTJ, dystrophin lines the membrane invaginations where myofibrils attach to the membrane. It is colocalized with talin, but is not related to the distribution of acetylcholine receptors (AChRs) which are clustered at the postsynaptic membrane in the vicinity of the MTJ in these fibers. We found that the localization of dystrophin can be induced in cultured Xenopus myotomal muscle cells by treating them with polystyrene latex beads. Dystrophin is discretely localized at the bead-muscle contacts. With electron microscopy, a sarcolemma specialization with all the salient features of the MTJ, including basal lamina-lined membrane invaginations along which myofibrils make attachment. Although these beads also induce clustering of AChRs, the patterns of dystrophin and AChR localization are distinct. The appearance of dystrophin at the bead-contacted sarcolemma is coincident with the development of the membrane invaginations. This, together with its concentration along membrane invaginations at the MTJ in vivo, suggests a role for dystrophin in the formation of this junctional specialization. Since the signal for MTJ development can be presented to cultured muscle cells in a temporally and spatially controlled manner by beads, this system offers a simple model for analyzing the mechanism of this sarcolemma specialization.

Key words: dystrophin, myotendinous junction, MTJ, acetylcholine receptor clusters, Xenopus.

\section{Introduction}

Dystrophin is a sarcolemma-associated protein that is encoded by the gene responsible for the Duchenne and Becker types of muscular dystrophy (Hoffman et al. 1987; Hoffman and Kunkel, 1989). Its amino acid sequence shares homology with the spectrin $/ \alpha$-actinin family of cytoskeletal proteins that are important for normal membranecytoskeleton interactions (Koenig et al. 1988; Davison and Critchley, 1988; Hoffman et al. 1989; Byers et al. 1989; Bennett, 1990). Immunocytochemical studies have shown the localization of this protein on the inside of the plasma membrane in normal skeletal muscle (Zubrzycka-Gaarn et al. 1988; Watkins et al. 1988; Arahata et al. 1988; Byers et al. 1991). This suggests that dystrophin may play a major role in stabilizing the muscle membrane against mechanical damage due to contraction and in the maintenance of other membrane structures in normal muscle (Engel, 1986; Mandel, 1989).

The myotendinous junction (MTJ) is a highly specialized domain of the sarcolemma that mediates the transmission of force generated by contracting myofibrils to the tendon.
This is a site on the sarcolemma that is vulnerable to mechanical damage (Garrett and Tidball, 1988). In normal muscle, it is marked by extensive membrane invaginations which greatly increase the surface area for the attachment of myofibrils on the inside and the tendon on the outside of the membrane, thus reducing the force load experienced by each unit area of sarcolemma (Trotter et al. 1981; Trotter, 1985; Tidball and Daniel, 1986). An extensive array of proteins, encompassing intracellular, transmembrane and extracellular kinds, are concentrated at the MTJ (Tidball et al. 1986; Swasdison and Mayne, 1989; Turner et al. 1991; Bozyczko et al. 1989; Chen et al. 1990). These proteins presumably form a complex to secure the linkage of contractile elements with both the membrane and the tendon and to ensure the integrity of the muscle fiber during contraction. Recent studies have shown an elevation in the amount of dystrophin at this specialization relative to the rest of the sarcolemma (Shimizu et al. 1989; Samitt and Bonilla, 1990; Byers et al. 1991). This enrichment of dystrophin may be highly significant for the normal activities of the MTJ, according to the recent observation of Tidball and Law (1991), who reported an alteration of the mem- 
brane architecture as evidenced by the diminution in membrane invaginations at the MTJ in skeletal muscle of the $m d x$ mouse. This animal, similar to human patients with Duchenne dystrophy, is genetically deficient in dystrophin (Torres and Duchen, 1987; Hoffman et al. 1987; Hoffman and Kunkel, 1989). Thus this protein may be involved in the formation and/or the maintenance of the membrane topography at the MTJ. In addition, dystrophin has been localized to the acetylcholine receptor (AChR)-rich postsynaptic membrane of Torpedo electric organ and the neuromuscular junction (NMJ) in skeletal muscle (Shimizu et al. 1989; Chang et al. 1989; Jasmin et al. 1990; Sealock et al. 1991; Byers et al. 1991; Yeadon et al. 1991), where extensive cytoskeleton-membrane interactions also take place (Bloch and Pumplin, 1988; Froehner, 1991).

To understand the function of dystrophin in the formation of normal MTJ, it is desirable to have a simple model system in which the development of the junctional complex can be experimentally manipulated. Although previous studies have examined MTJ development both in vivo and in vitro (Tidball and Lin, 1989; Swasdison and Mayne, 1991), these systems have not been very useful in deciphering the cellular and molecular mechanisms in junction formation. Previously we showed that the development of the postsynaptic membrane can be elicited by latex beads in cultured Xenopus myotomal muscle cells (Peng and Cheng, 1982). Recently, we presented evidence that these beads also effect development of a MTJ-like specialization at bead-muscle contacts (Rochlin et al. 1989). This has allowed us to examine the relationship between various cytoskeletal proteins known to be concentrated at the MTJ and the development of this specialization. In this study, we studied the localization of dystrophin in relationship to the bead-induced MTJ-like specialization in these cultured muscle cells and contrasted it with the localization of this protein in vivo. We report here that the stimulation by beads induces localization of dystrophin and this process is closely related to the formation of MTJ-type membrane invaginations. Thus, this bead-muscle coculture offers a simple model system for understanding the assembly of the protein complex at the MTJ.

\section{Materials and methods}

\section{Materials}

Two different antibodies against dystrophin were used in this study. Monoclonal antibody 1958, kindly provided by Dr. Stanley Froehner (University of North Carolina at Chapel Hill), was originally raised in mice against peripheral membrane proteins in Torpedo AChR-rich membrane. It has been shown to recognize specifically dystrophin from Torpedo, mouse and Xenopus tissues (Sealock et al. 1991). The second probe is an antiserum raised in sheep against a $60 \mathrm{kDa}$ fusion protein of mouse dystrophin (kindly provided by Dr. Eric Hoffman, University of Pittsburgh). An antibody raised in rabbit against chicken gizzard talin (Burridge and Connell, 1983) was a kind gift from Dr. K. Burridge (University of North Carolina at Chapel Hill). FITC- or rhodamine-conjugated secondary antibodies were purchased from Organon Technica (Durham, NC). Tetramethyl rhodamine-conjugated $\alpha$-bungarotoxin (R-BTX) was obtained from Molecular Probes (Portland, OR). Polyornithine and collagenase were obtained from Sigma
(St. Louis, MO). Recombinant human basic fibroblast growth factor (bFGF) was a kind gift from Synergen (Boulder, CO).

\section{Western blots}

Western blot analyses of Xenopus muscle were carried out to demonstrate antibody cross-reactivity. These studies were carried out with microsomal membrane preparations from both the leg muscles of adult frogs and the tail muscles of tadpoles. Hind leg muscles of adult frogs or tails of stage 50 tadpoles were homogenized in a buffer containing $0.1 \mathrm{M} \mathrm{NaCl}, 10 \mathrm{mM}$ Hepes, $1 \mathrm{mM}$ EGTA, $1 \mathrm{mM}$ PMSF (phenylmethylsulfonyl fluoride), $50 \mathrm{ng} / \mathrm{ml}$ pepstatin, $500 \mathrm{ng} / \mathrm{ml}$ leupeptin, $500 \mathrm{ng} / \mathrm{ml}$ aprotinin, $500 \mathrm{ng} / \mathrm{ml}$ antipain, $\mathrm{pH} 7.4$, with a Tekmar (Cincinnati, $\mathrm{OH})$ tissuemizer. The homogenate was centrifuged at $5,000 \mathrm{revs} / \mathrm{min}$ for $20 \mathrm{~min}$ at $4^{\circ} \mathrm{C}$ with a Sorvall RC-2 centrifuge and a SA600 rotor. The supernatant was filtered through 4 layers of cheese cloth on ice and centrifuged at $32,000 \mathrm{revs} / \mathrm{min}$ for $30 \mathrm{~min}$ at $4^{\circ} \mathrm{C}$ with a Beckman centrifuge and a Ti75 rotor. The pellet was resuspended in extraction buffer $(0.3 \mathrm{M}$ sucrose, $0.6 \mathrm{M} \mathrm{KCl}, 0.1 \mathrm{mM}$ EGTA, $0.1 \mathrm{mM}$ $\mathrm{CaCl}_{2}, 10 \mathrm{mM}$ Pipes, $\mathrm{pH}$ 7.0) and homogenized. The suspension was centrifuged through a discontinuous sucrose gradient at $38,000 \mathrm{revs} / \mathrm{min}$ overnight with a Ti75 rotor at $4^{\circ} \mathrm{C}$. The material at the $30 \%$ to $40 \%$ sucrose interface was collected, washed with water, pelleted and resuspended in $10 \mathrm{mM}$ Pipes buffer ( $\mathrm{pH} 6.8$ ) containing $0.3 \mathrm{M}$ sucrose. Aliquots were stored at $-80^{\circ} \mathrm{C}$. AChRrich postsynaptic membranes from Torpedo electric organ were used for comparison with the Xenopus tissue. These were prepared according to Porter and Froehner (1983) and kindly provided by Dr. R. Sealock (University of North Carolina at Chapel Hill).

For western blots, the membrane preparations were mixed with SDS sample buffer, boiled for $5 \mathrm{~min}$ and electrophoresed on a 7.5\% SDS-polyacrylamide gel (Laemmli, 1970). Proteins were transferred to Immobilon membrane (Millipore, Bedford, MA) with a semi-dry electrophoretic transfer device (Pharmacia-LKB, Gaithersburg, MD) at a current density of $0.8 \mathrm{~mA} / \mathrm{cm}^{2}$ for $1 \mathrm{~h}$ (Towbin et al. 1979). The transfer buffer consisted of $39 \mathrm{mM}$ glycine, $48 \mathrm{mM}$ Tris, $10 \%$ methanol and $0.2 \%$ SDS ( $\mathrm{pH} \mathrm{8.3).}$ After blocking the membrane with $2 \%$ BSA, $0.05 \%$ Tween-20 in Tris-buffered saline, it was probed with the anti-dystrophin antibody for $90 \mathrm{~min}$. After washing, it was incubated with alkaline phosphatase-conjugated secondary antibody. Protein bands were visualized by reacting the membrane with color development substrate solution kit (Promega, Madison, WI) containing nitro blue tetrazolium (NBT) and 5-bromo-4-chloro-3-indolyl phosphate (BCIP) according the manufacturer's instructions.

\section{Preparation of myotomal muscle fibers and cultures}

Myotomal muscle fibers were prepared according to previously published methods (Chen et al. 1990). In short, tails of anesthetized Xenopus tadpoles were excised, skinned and dissociated with collagenase at a concentration of $3 \mathrm{mg} / \mathrm{ml}$ in frog Ringer solution for $2 \mathrm{~h}$ at room temperature. At the end of the incubation period, the tails were gently vortexed to release the muscle fibers, which were collected by centrifugation.

Myotomal muscle cultures were prepared from Xenopus embryos following previously published methods (Peng et al. 1991a). In short, the dorsal portions of the embryos at stage 2022 were dissected out and dissociated in a $\mathrm{Ca}^{2+}, \mathrm{Mg}^{2+}$-free solution. The cells were then plated onto coverglasses for immunofluorescence studies or into $35 \mathrm{~mm}$ Lux Contur Permanox tissue culture dishes (Miles Scientific, Naperville, IL) for electron microscopy. They were cultured at $22^{\circ} \mathrm{C}$.

\section{Induction of membrane specializations with beads}

Polypeptide-coated beads were used to induce the formation of membrane specializations in this study following procedures pre- 
viously used in our laboratory (Peng and Cheng, 1982; Peng et al. 1991b). Two different polypeptides were used in this study. In our earlier experiments, we applied cationic polyornithine-coated beads to muscle cultures. In more recent studies, beads coated with recombinant bFGF were found to be equally effective. The coating was done by incubating ethanol-washed polystyrene beads ( $4.5 \mu \mathrm{m}$ or $10 \mu \mathrm{m}$ in diameter) with the polypeptide solution at a concentration of 0.1 to $1 \mathrm{mg} / \mathrm{ml}$ in PBS overnight at $4{ }^{\circ} \mathrm{C}$, followed by washes with phosphate-buffered saline. The beads were applied to muscle cultures and incubated for a period of time from several hours to four days. This procedure resulted in the formation of specializations at an average of $70 \%$ bead-muscle contacts. An additional method of bead application was experimented with in this study. Instead of applying coated beads to muscle cultures, we pretreated them with bFGF at a concentration of $1 \mu \mathrm{g} / \mathrm{ml}$ for $1 \mathrm{~h}$, washed the cultures to remove the excess bFGF and applied ethanol-washed, native beads. Our recent studies have shown that this exogenously applied bFGF binds to the cell surface, presumably to heparan sulfate proteoglycans, and can be presented to the muscle membrane at sites of bead-muscle contacts (L.P. Baker, Q. Chen and H.B. Peng, unpublished data). This procedure resulted in the formation of specializations at a higher number of bead-muscle contacts. It is not uncommon to have more than $90 \%$ of bead-muscle contacts exhibiting specializations with this method.

\section{Immunofluorescence}

Dissociated myotomal muscle fibers were fixed for $30 \mathrm{~min}$ with a fixative developed for the Xenopus culture by Luther and Bloch (1989), composed of $0.5 \%$ paraformaldehyde, $80 \mathrm{mM}$ cyclohexylamine in $10 \mathrm{mM}$ Pipes buffer containing $10 \mathrm{mM} \mathrm{MgCl}_{2}$ and 10 mM EGTA, pH 6.5, and washed with $75 \mathrm{mM}$ Tris-HCl buffer $(\mathrm{pH}$ 6.7) containing $10 \mathrm{mM} \mathrm{MgCl}_{2}$ and $0.5 \%$ Brij 58 for $1 \mathrm{~h}$. Nonspecific binding sites were blocked with $20 \mathrm{mM}$ Tris-HCl buffer containing $0.1 \% \mathrm{BSA}$ and $10 \mathrm{mM} \mathrm{MgCl} 2$ ("blocking buffer") for $1 \mathrm{~h}$. They were then labeled with anti-dystrophin antibodies reconstituted in the blocking buffer, overnight at $4^{\circ} \mathrm{C}$. The fibers were washed and labeled with appropriate fluorescently conjugated secondary antibody and mounted on slides. To visualize dystrophin and talin in the same fiber, we labeled fibers with a mixture of antibodies against these two proteins and then with a mixture of appropriate secondary antibodies conjugated with contrasting fluorochromes. To visualize AChR clusters in the postsynaptic membrane, fibers were labeled with $0.3 \mu \mathrm{M}$ R-BTX immediately after fixation.

Cultured muscle cells were fixed with $95 \%$ ethanol at $-20^{\circ} \mathrm{C}$ for $5 \mathrm{~min}$, washed with blocking buffer and labeled with antibodies as described above. For visualization of AChR clusters, cultures were labeled with R-BTX prior to fixation.

Conventional fluorescence microscopy was carried out with a Leitz Orthoplan microscope equipped with epifluorescence illumination. Confocal microscopy was conducted on a Nikon inverted microscope equipped with a Biorad MRC-600 laser scanner. Optical sections $0.5-2 \mu \mathrm{m}$ in thickness were obtained and reconstructed with the BioRad software.

\section{Electron microscopy}

Cultures were fixed with $1 \%$ glutaraldehyde in $0.05 \mathrm{M}$ cacodylate buffer $\left(\mathrm{pH}\right.$ 7.2) for $2 \mathrm{~h}$, washed and postfixed with $1 \% \mathrm{OsO}_{4}$ for $1 \mathrm{~h}$. They were then stained with $1 \%$ uranyl acetate in $50 \mathrm{mM}$ acetate buffer ( $\mathrm{pH} 5.5)$ for $2 \mathrm{~h}$, dehydrated through an ethanol series and embedded in Epon. After the block was removed from the dish, single cells were marked with a Leitz diamond marker mounted on the nosepiece of a compound microscope and cut out with a jeweler's saw. The cell blocks were mounted on blank Epon blocks and sectioned perpendicular to the original culture substratum. The sections were stained with uranyl acetate and lead citrate and examined with a JEOL 100CX electron microscope.

To quantify the membrane invaginations at bead-muscle contacts, we measured the length of the membrane profile $\left(L_{\mathrm{m}}\right)$ and the length of the bead profile $\left(L_{\mathrm{b}}\right)$ at the site of contact in electron micrographs. The percentage increase in the length of membrane profile as a result of invagination is calculated by the formula:

$\%$ increase in membrane profile length $=\left[\left(L_{\mathrm{m}}-L_{\mathrm{b}}\right) / L_{\mathrm{b}}\right] \times 100 \%$. These measurements were carried out with an IBM personal computer and a Houston Instruments Hipad digitizer, using the Sigma Scan software (Jandel Scientific, San Rafael, CA).

\section{Results}

\section{Detection of Xenopus dystrophin by western blots}

To demonstrate the specificity of the antibodies for Xeno pus dystrophin, we conducted western blot analyses on membrane preparations from adult and tadpole skeletal muscle. The antibodies used in this study were well characterized in previous studies (Hoffman et al. 1987; Sealock et al. 1991). They only recognize dystrophin and do not cross-react with the recently discovered relative of dystrophin, the dystrophin-related protein (Love et al. 1991; Khurana et al. 1990; Thi Man et al. 1991; Ohlendieck et al. 1991) in mammalian muscle. Since one of the antibodies used in this study (mAb 1958) was prepared against Torpedo postsynaptic membrane, we compared the dystrophin band in this tissue with the Xenopus sample in the same experiments. Fig. 1 shows the western blots of muscle samples prepared from adult muscle. Both mAb 1958 (lanes A-M) and the anti-60 kDa antibody (lanes B-M) recognized a single band with an apparent molecular mass of about $300 \mathrm{kDa}$ in the Xenopus muscle sample. A band of similar molecular mass was also recognized by both antibodies in Torpedo postsynaptic membrane preparations (lanes A-T and B-T). The presence of dystrophin in the postsynaptic membrane of Torpedo electric organ has recently been demonstrated. These data suggest that these antibodies can detect a protein homologous to dystrophin in Xenopus skeletal muscle membrane. Similar results were also obtained when membrane preparations from tadpole muscles were used.

\section{Localization of dystrophin at the MTJ in the myotomal muscle fibers}

Immunofluorescence studies were conducted to determine the localization of dystrophin in the myotomal muscle fibers from mature Xenopus tadpoles. These fibers can be easily dissociated from the tails of the tadpoles by collagenase treatment. The ends of these fibers elaborate into MTJs and are the site of motor innervation. Thus, MTJ and NMJ specializations are located in adjacent but distinct membrane domains which are retained in dissociated fibers. When the muscle fibers were labeled with either of the two anti-dystrophin antibodies and examined in whole mount, the most prominent staining was at their ends as shown in Fig. 2. Lateral views of these fibers showed intense antibody stain- 


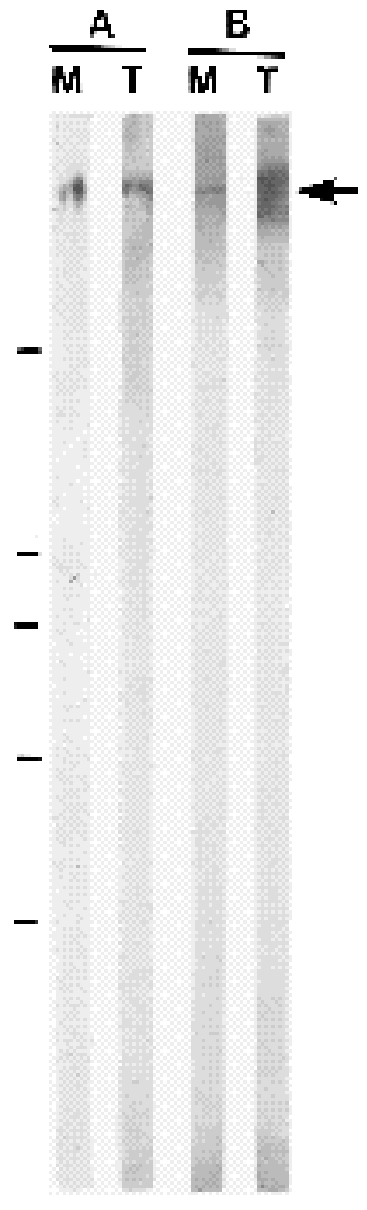

Fig. 1. Western blots of Xenopus muscle membrane sample (M) and Torpedo AChR-rich membrane sample (T) probed with antidystrophin antibodies: mAb 1958 (A) and anti-60 kDa polyclonal antiserum (B). A band at a molecular mass of about $300 \mathrm{kDa}$ was recognized in each sample (arrow). This value was extrapolated from the positions of the molecular mass standards indicated on the left (from top to bottom): $200 \mathrm{kDa}, 116.25 \mathrm{kDa}$ $97.4 \mathrm{kDa}, 66.2 \mathrm{kDa}, 45 \mathrm{kDa}$. The broad band in B-T was a result of sample overloading.

ing in a series of streaks confined to the ends of the fibers. This labeling pattern is reminiscent of the deep membrane invaginations at the MTJ as revealed by electron microscopy (Nakao, 1976; Trotter et al. 1981) or by immunofluorescent labeling with antibodies against vinculin or talin, two proteins known to be concentrated at the MTJ (Shear and Bloch, 1985; Tidball et al. 1986; Chen et al. 1990). Thus, dystrophin appears to be concentrated along the sarcolemma invaginations at the MTJ. Muscle fibers not permeabilized by detergent were not stained, nor were permeabilized fibers that were labeled with fluorescent secondary antibody alone without first labeling with primary antibodies (data not shown).

To ensure that the apparent intensity of labeling was not simply due to superimposition of membrane invaginations in whole mounts, antibody-labeled muscle fibers were also observed by confocal fluorescence microscopy. The labeled fibers were first optically sectioned to a thickness of 0.5 to $2 \mu \mathrm{m}$. The sections were then examined individually or reconstructed to generate a 3-dimensional view of the entire fiber. As shown in Fig. 3 a and b, the most intense staining was still confined to finger-like structures at the ends of these fibers. The fluorescent intensity at these sites was approximately ten times brighter than the extrajunctional sarcolemma as determined in digital images. Thus, with both conventional and confocal microscopy, we found dystrophin staining of the MTJ to be markedly elevated in comparison to the non-junctional sarcolemma.

Colocalization of dystrophin with talin, but not with AChR clusters

As mentioned above, the sarcolemma at MTJ is marked by a complex of cytoskeletal proteins. Talin is one of these proteins which lines the invaginated membrane at the MTJ (Tidball et al. 1986; Rochlin et al. 1989). To understand the relationship between talin and dystrophin, we doublelabeled the myotomal muscle fibers with mAb 1958 and a rabbit antibody against talin. This anti-talin antibody has previously been shown to recognize the Xenopus protein (Rochlin et al. 1989). Fig. 4a-b shows an MTJ viewed from the end. This view reveals a complicated pattern of membrane invaginations. The correspondence in the distribution of these two molecules is evident in every detail and was observed in every fiber examined. Thus, talin and dystrophin are exactly colocalized at the MTJ.

To determine whether the cholinergic postsynaptic membrane in the myotomal fibers is enriched in dystrophin as it is in Torpedo electric tissue, fibers were double-labeled with R-BTX and mAb 1958. Fig. 4c, shows a view of the end of a muscle fiber where dystrophin lines the finger-like structures of the MTJ. When the same area was examined by R-BTX fluorescence, an entirely different pattern of staining emerged, as shown in Fig. 4d. AChR clusters visualized by R-BTX staining bear no relationship to the MTJ fingers, although the clusters intermingled with these dystrophin-rich structures. In fact, areas with complementary dystrophin and AChR distribution could be detected. An example is pointed out by arrowheads in Fig. 4c-d. In this area, AChR clusters existed in a dystrophin-poor membrane domain. This suggests that AChR clusters and dystrophin exist in adjacent, but microscopically separate, regions. Furthermore, we examined fibers that were only innervated at one of the two ends. At the synapse-free end, which was free of AChR clusters (Fig. 4f), dystrophin staining of the MTJ was still seen. These data thus clearly show that dystrophin is associated with the MTJ and not with the postsynaptic membrane of the myotomal muscle fibers.

\section{Induction of MTJ-like specialization by latex beads}

To understand the role of dystrophin in the biogenesis of the MTJ, we turned to cultured Xenopus myotomal muscle cells. These cells are the in vitro counterpart of the tadpole tail muscle fibers described above. Our previous studies have shown that polystyrene latex beads can induce the formation of AChR clusters in these cultures (Peng and Cheng, 1982). In addition, deep membrane invaginations with structural features analogous to those at the MTJ also develop at the membrane in contact with beads (Rochlin et al. 1989). When these contacts were examined by electron microscopy, the membrane invaginations exhibited a striking resemblance to the MTJ in skeletal muscle. Two examples are shown in Fig. 5a-b: myofibrils impinged on electron-dense membrane plaques along the invagination (white arrows in Fig. 5a-b); and extracellular matrix, in the form of basal lamina, appeared along the membrane invagination (black open arrows in Fig. 5a-b). Thus, bead-muscle contact stimulates the formation of a MTJ-like specialization. Along the same bead-muscle contact, one could also observe membrane densities not in association with myofib- 

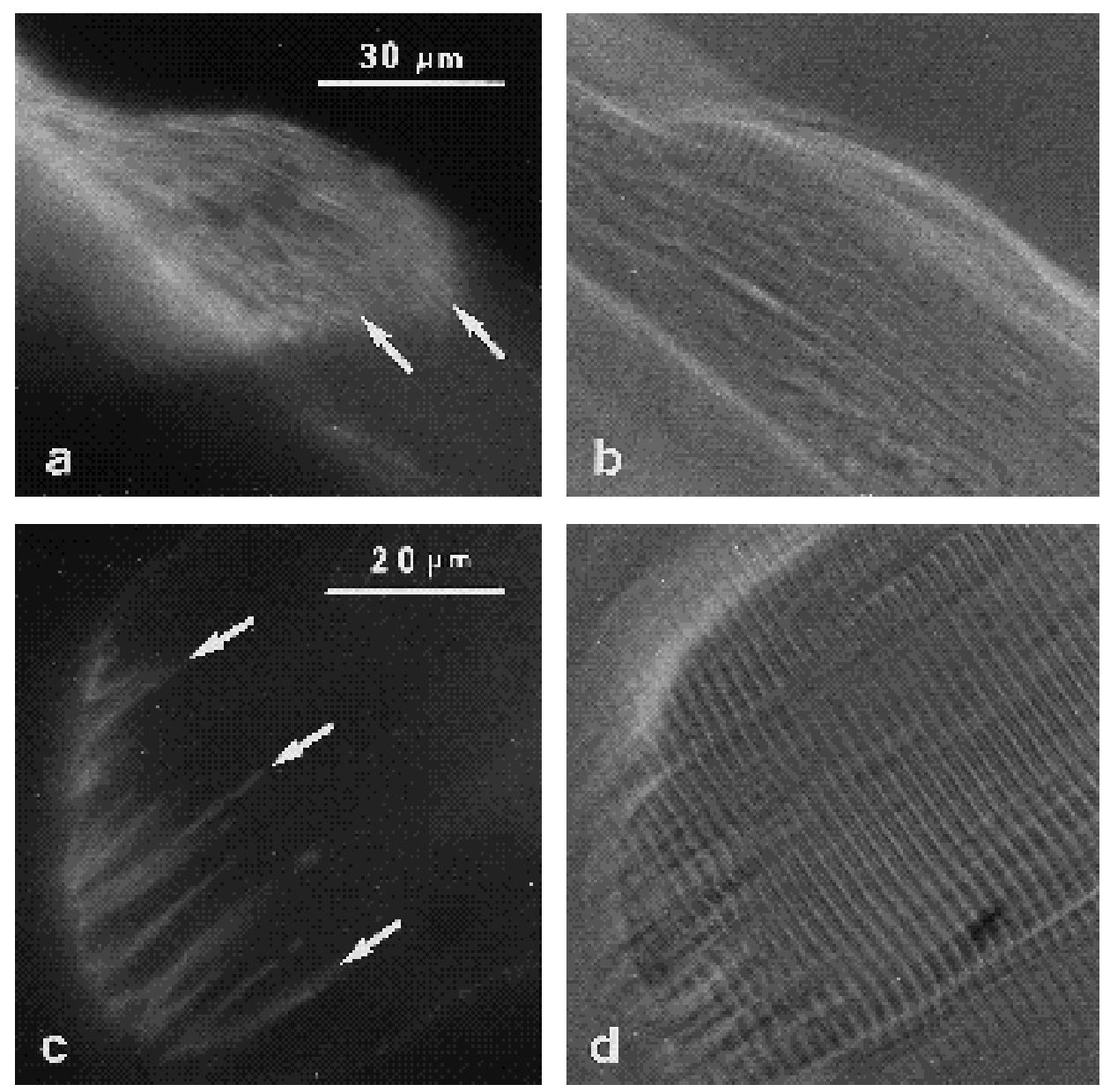

Fig. 2. Localization of dystrophin at the MTJ of dissociated Xenopus myotomal muscle fibers in whole mount with conventional fluorescence microscopy. (a) mAb 1958 labeling; (c) anti-60 kDa labeling. A series of streaky structures (arrows) at the ends of these fibers were labeled.

(b and d) show the ends of these fibers in phase-contrast.

rillar insertion (black-on-white arrowheads in Fig. 5b). These patches were presumably sites of AChR concentration as suggested by the similarities in their scalloped appearance to AChR-rich domains in electric tissue and in muscle, in electron micrographs (Kullberg et al. 1977; Sealock and Kavookjian, 1980). Thus, like myotomal muscle fibers in vivo, AChR clusters are intermingled with MTJ-like specializations at bead-muscle contacts.

When beads first came into contact with the muscle cell, the membrane was congruent with the bead surface. Previously we showed that a meshwork of actin filaments develops shortly after the contact is established (Peng and Phelan, 1984). However, myofibrils traverse underneath these early contacts without contacting them (Peng and Cheng, 1982). As the membrane became invaginated during subsequent development of the specialization at the bead-muscle contact, the attachment of myofibrils with it as shown in Fig. 5a became apparent. Electron microscopic studies showed that the formation of myofibrillar insertion into the contact area was coincident with the development of the deep membrane invaginations. The invagination process occurred slowly relative to the formation of $\mathrm{AChR}$ clusters at the bead. We quantified the time course on the development of membrane invaginations from electron micrographs by calculating the percentage increase in the length of membrane profile at the bead-muscle contact as described before. As shown in Fig. 6b, the length of the membrane profile showed a $20 \%$ increase after the first day. This process continued at least through the first 4 days of bead-msucle contact. At that time, the membrane profile showed a $60 \%$ increase in length as a result of invagination. The development of the invagination is slow, however, when compared with the clustering of AChRs. As shown in Fig. 6a (filled bars), the number of bead-associated clusters had already reached its full expression after just one day.

\section{Localization of dystrophin at the bead-muscle contacts}

Since dystrophin was localized at the myotomal MTJ in vivo, we examined whether it was also present at the beadinduced MTJ-like structures, by immunofluorescence using both mAb 1958 and the anti-60 kDa fusion protein antibodies. Since not every bead-muscle contact induced the formation of membrane specializations, we used the clustering of AChRs as a positive indicator of the beads' stimulatory effect. By double-labeling cultures with R-BTX and antibodies against dystrophin, we correlated the localization of these two proteins at bead-muscle contacts. As shown in Fig. 7a and d, dystrophin was concentrated at the bead-muscle contacts. These sites invariably showed AChR clustering (Fig. 7b and e). However, when the patterns of staining were compared, it was clear that dystrophin and AChRs were accumulated at different domains at the beadmuscle contacts (Fig. 7). This is further illustrated in Fig. 8. In this mAb 1958- and R-BTX-labeled preparation, dis- 

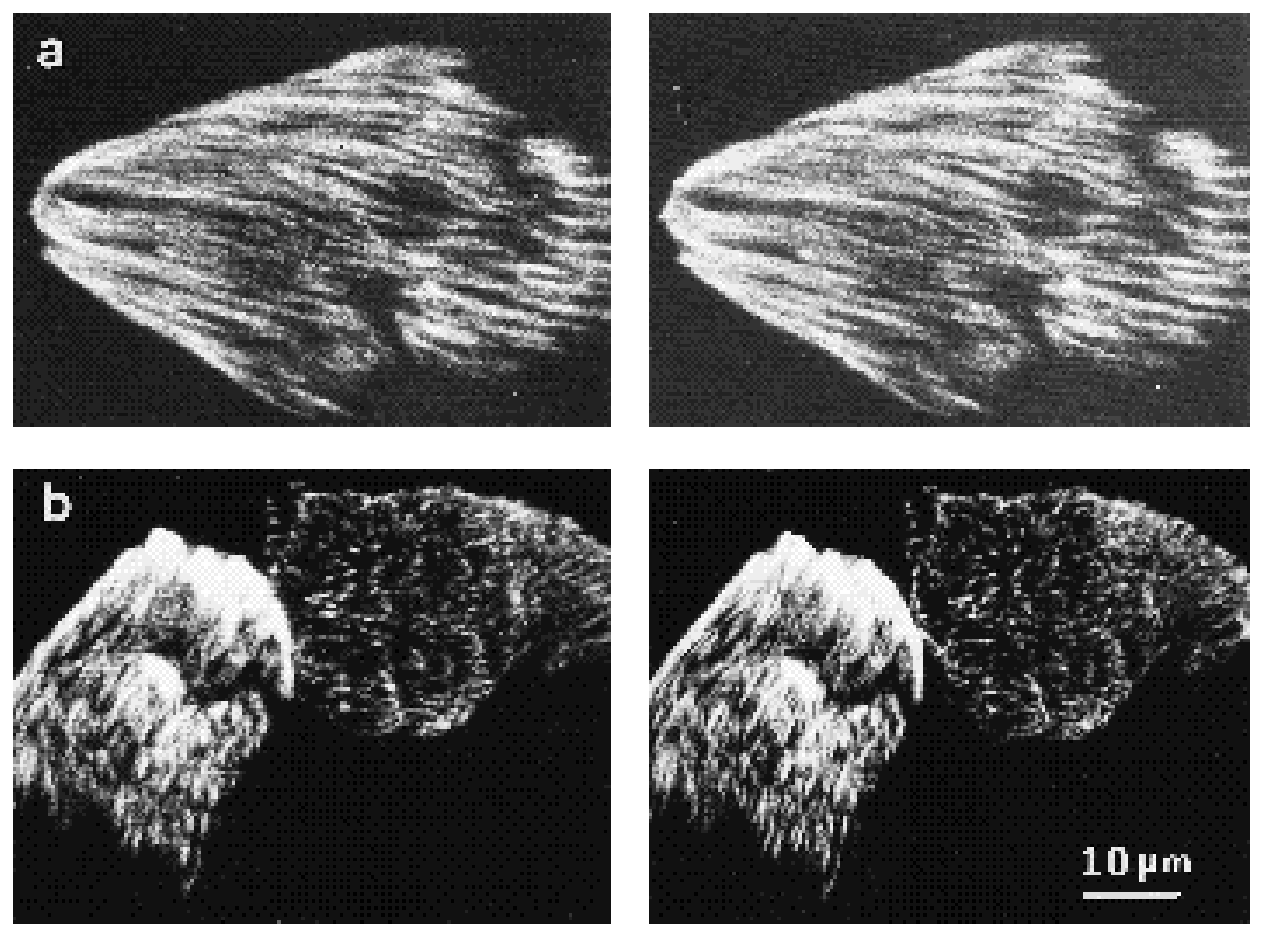

Fig. 3. Confocal stereo views of dystrophin localization at the MTJ in vivo $(a, b)$ and at the bead-muscle contacts in vitro (c). These samples were labeled with mAb 1958. They were optically sectioned at a
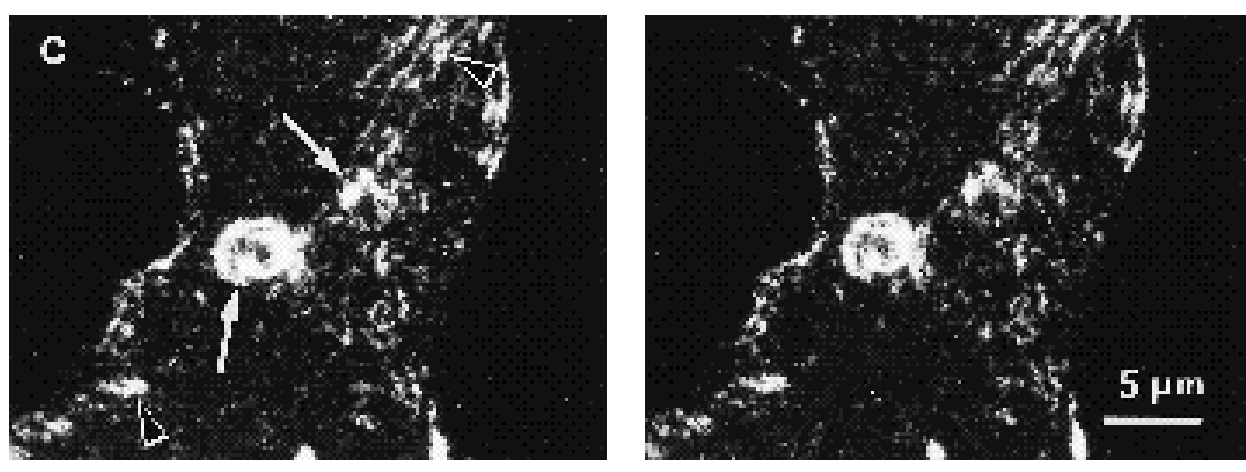
thickness of $2 \mu \mathrm{m}$ (a), $1 \mu \mathrm{m}$ (b) or $0.5 \mu \mathrm{m}$ (c) to obtain a stack of images from each cell with a confocal microscope. These images were then combined and shifted by 1 pixel to generate the stereo views. The number of sections represented in each image were 23 in a, 41 in b and 15 in c. In c, the white arrows point to bead-muscle contacts and the black-on-white arrowheads point to sites of cell-substratum contacts that were also dystrophin-positive. Bars, same for $a$ and $b$.

tinct patterns of dystrophin (Fig. 8a, c) and AChR (Fig. 8b, d) localization at the bead-muscle contacts were obvious. In fact, AChR clusters often occupied membrane domains devoid of dystrophin labeling (arrowheads in Fig. 8c, d).

Furthermore, the time course in the development of these two specializations also showed clear differences. This was quantified by first scoring the percentage of bead-muscle contacts that were positive for R-BTX staining, thus indicating AChR clustering, and then scoring these contacts that were also positive for mAb 1958 staining. This is shown in Fig. 6A (open bars). At 24 h, only $30 \%$ of the AChRpositive bead-muscle contacts exhibited dystrophin localization. This ratio increased to $60 \%$ after 2 days and to $90 \%$ after 4 days of bead-muscle coculture. Thus, in contrast to AChR clustering, dystrophin appeared at bead-muscle contacts with a much slower time course.

To compare the rate of development of three types of specializations induced by beads, namely, AChR clustering, dystrophin accumulation and membrane invagination, we replotted the data shown in Fig. 6A and B by normalizing them to their respective $96 \mathrm{~h}$ values in Fig. 6C. This plot shows that the time course of dystrophin accumulation is in good agreement with the formation of membrane invaginations, but both processes lag behind the formation of AChR clusters. This suggests that dystrophin is related to the mechanism for the formation of membrane invaginations.

In addition to bead-muscle contacts, dystrophin was also detected on the bottom of cultured muscle cells at sites of cell-substratum contact. Fig. 3c shows a pair of confocal stereo images of a mAb 1958-labeled cell. On the top membrane of this cell, two bead-muscle contacts with dystrophin localization can be seen (arrows in Fig. 3c). On the bottom of this cell, dystrophin was localized in punctate or linear structures that were identified as focal contacts with the substratum or sites of myofibril termination at the membrane in previous studies on these muscle cells (Chen et al. 1990; Kramarcy and Sealock, 1990). In the myotomal muscle culture, there exist several other non-muscle cell types, including fibroblasts, epithelial cells, melanocytes and neurons. However, none of these cell types showed detectable dystrophin staining, in agreement with previous results (Kramarcy and Sealock, 1990). On the other hand, sites of focal adhesions where stress fibers contacted the membrane were 

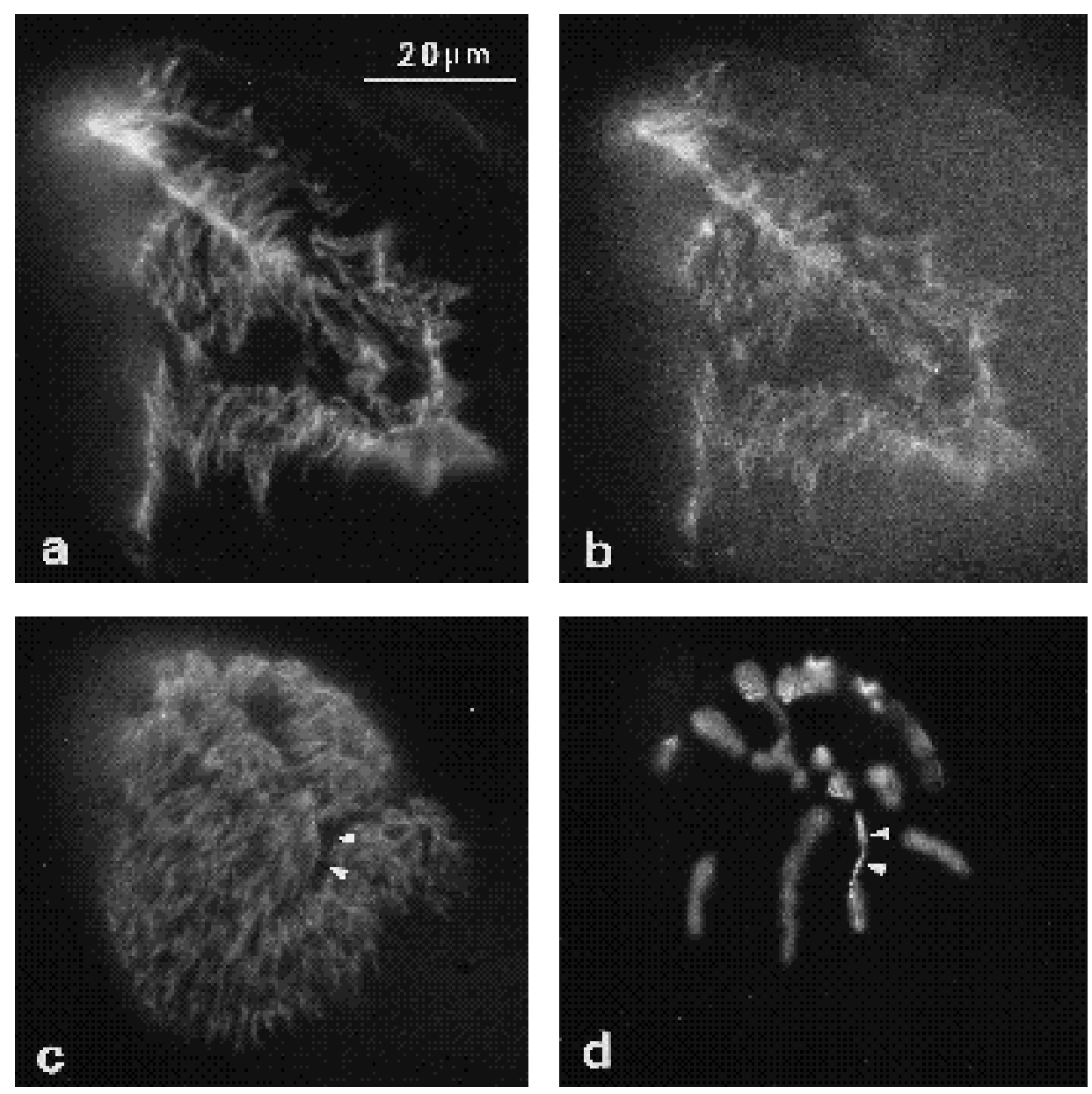

Fig. 4. Relationship of dystrophin (as revealed by mAb 1958 labeling) and other proteins at the MTJ. (a, b) Dystrophin (left) and talin (right). The colocalization is exact.
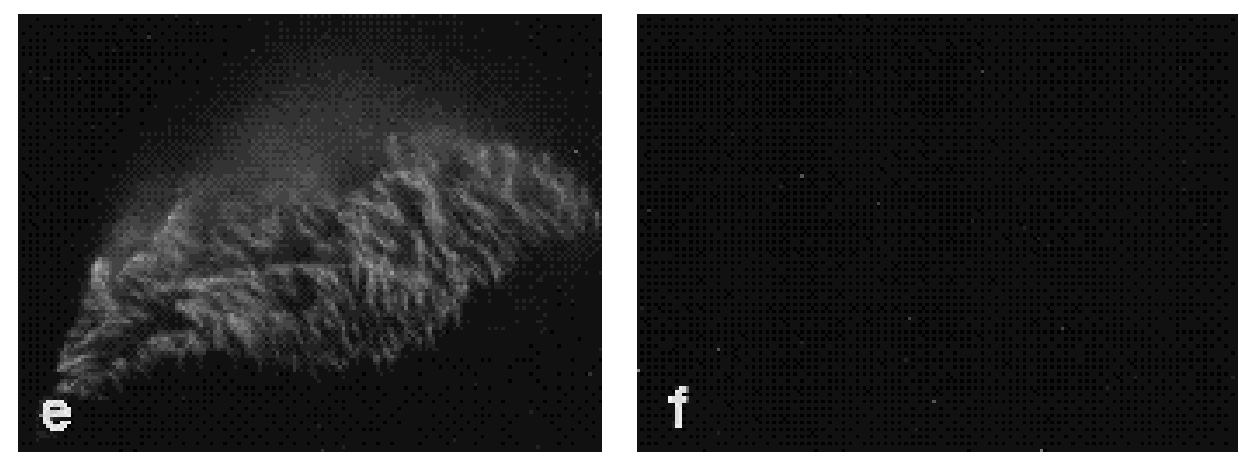
(c, d) Dystrophin (left) and AChR clusters (right). Although both proteins are present at the end of this myotomal fiber, they show very different, sometimes complementary, localization. An example is indicated by the arrowheads. At this site, the AChR cluster was located in a dystrophin-free area. (e, f) A noninnervated end of the myotomal fiber. Despite the absence of AChRs (f), the presence of dystrophin at the MTJ remains the same.

well marked by anti-talin antibodies in these non-muscle cells (data not shown; see Kramarcy and Sealock, 1990). Since stress fibers consist of bundles of actin filaments and possess contractile properties (Kreis and Birchmeier, 1980), they may be considered homologues of myofibrils in nonmuscle cells. The concentration of talin, but not dystrophin, at their attachment to the membrane illustrates the specific role that dystrophin plays in mediating the myofibril-membrane interaction in cultured Xenopus muscle cells.

\section{Discussion}

In this study, we have described the localization of dystrophin in Xenopus myotomal muscle fibers and in a tissue culture model that enables one to induce its localization in a spatially and temporally controlled manner. By wholemount fluorescence microscopy with both conventional and confocal optics, we found that dystrophin is highly concentrated at the MTJ of the myotomal muscle fiber. No staining of internal organelles or membranes was observed and the amount of staining fell steeply outside the MTJ domain of the sarcolemma. At the MTJ, dystrophin lines every branch of the invaginated membrane at the MTJ. In fact, dystrophin immunolabeling is an excellent marker for the extent of the MTJ. It may be argued that the intensity of the fluorescent staining is due to overlapping of the invaginated membranes. However, when the fiber was optically sectioned at a thickness of $0.5-2 \mu \mathrm{m}$ per slice in confocal imaging, such a concentration of dystrophin staining 

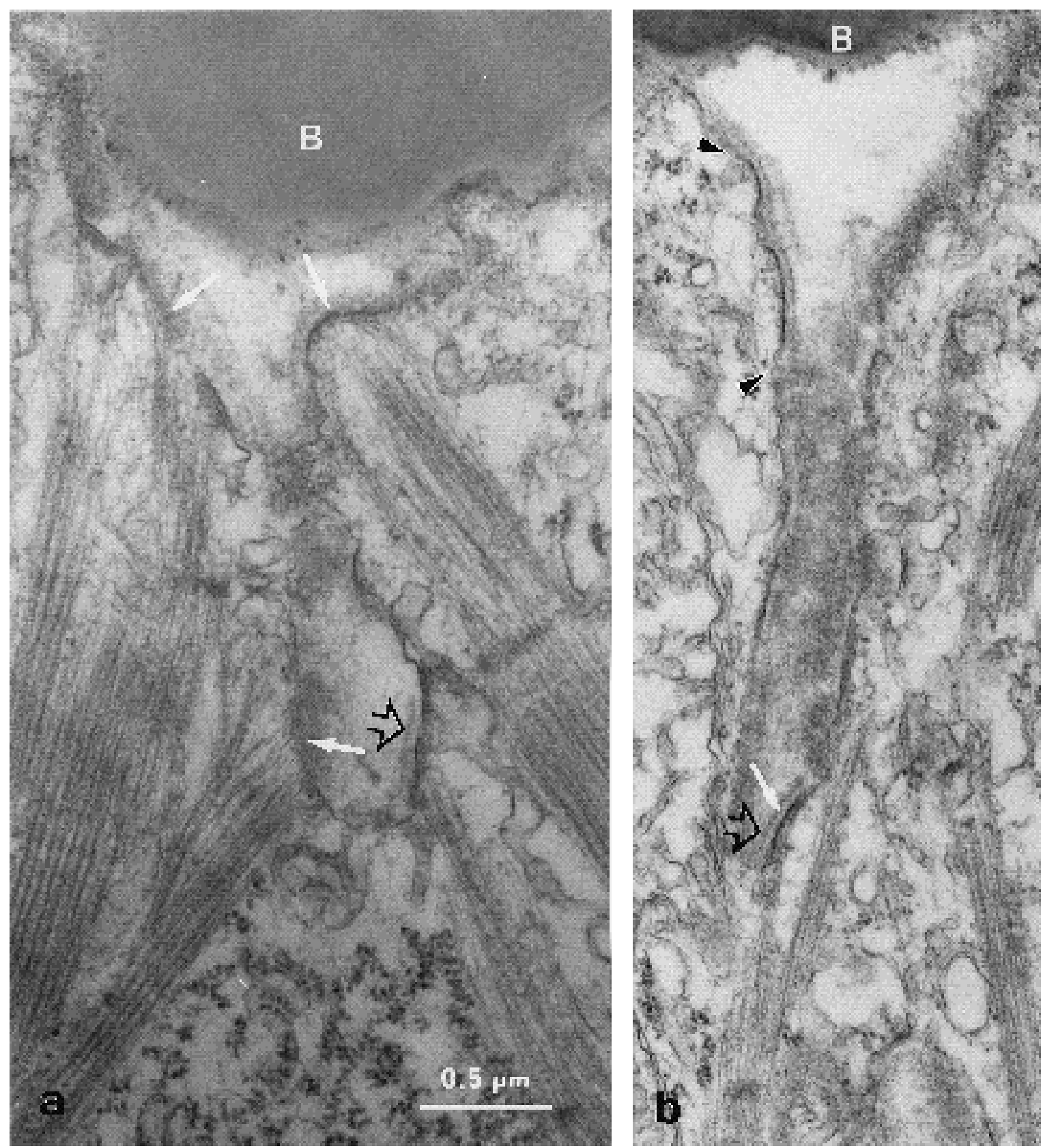

Fig. 5. Fine structure of the bead-muscle contacts in cultured muscle cells. Deep membrane invaginations are prominent features of these contacts with the bead (B). Along these invaginations, attachment of myofibrils with the sarcolemma (white arrows) can be seen. Basal lamina (open arrowheads) lines the extracellular surface of the invaginations. In $b$, a portion of the membrane along the invagination (between black-on-white arrowheads) is associated with an electron-density and basal lamina, but is not associated with myofibrils. This area is probably occupied by AChRs, based on its similarity to the structure of the NMJ in vivo in these myotomal fibers. These two beadmuscle contacts were $48 \mathrm{~h}$ old.

at the MTJ was still evident. Thus, this concentration is not artifactual. This result is in general agreement with previously published results (Shimizu et al. 1989; Samitt and Bonilla, 1990). Although previous studies have shown an association of this protein with both MTJ and the extrajunctional sarcolemma, recent localization at the electron microscopic level has shown a more intense immunolabeling at the former structure (Byers et al. 1991).

\section{MTJ localization of dystrophin}

The significance of the association of dystrophin with extrajunctional sarcolemma is not clear, since a normal lateral myofibril-sarcolemma structural relationship along this portion of the muscle fiber is still observed in the absence of dystrophin in the $m d x$ mouse (Tidball and Law, 1991). However, the structure of the MTJ is significantly altered in the $m d x$ mouse. The most obvious change is a diminu- 

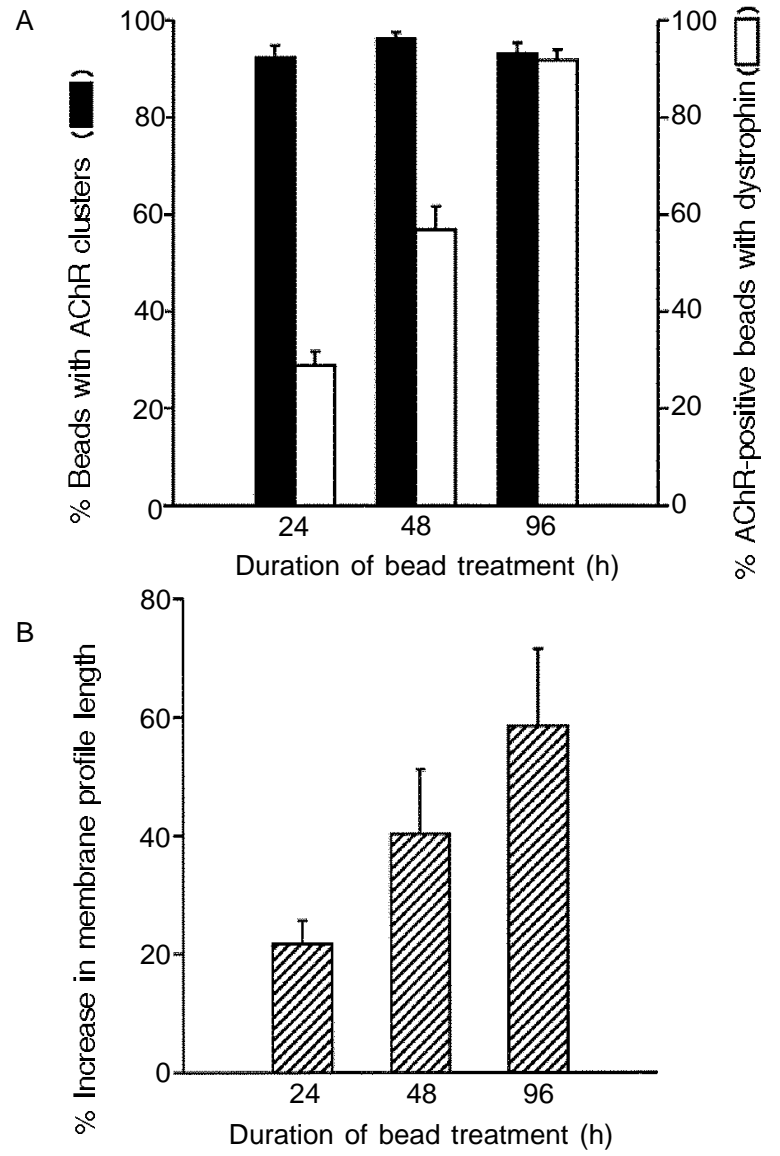

C

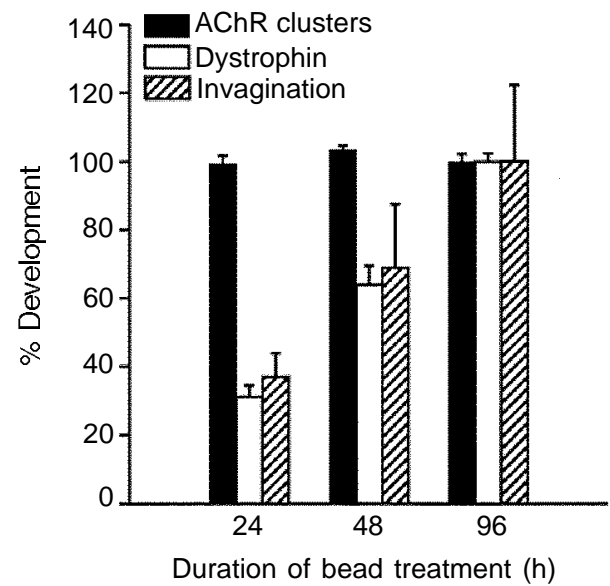

Fig. 6. Development of dystrophin localization at bead-muscle contacts in relationship to membrane invagination and AChR cluster formation in cultured muscle cells. For dystrophin and AChR labeling, cultures were double labeled with R-BTX and mAb 1958 followed by FITC-conjugated secondary antibody. (a) Percentage of bead-muscle contacts that were associated with AChR clusters (filled bars) and the percentage of those clusters that also showed dystrophin accumulation (open bars). At each time point, 20 cells with an average of 8 bead-muscle contacts per cell were scored. (b) Percentage increase in the length of membrane profile as a result of bead-induced invagination. An average of 11 bead-associated membrane profiles was analyzed for each time point from electron micrographs according to the formula given in Materials and methods. (c) Data in a and b are replotted by normalizing to their respective $96 \mathrm{~h}$ values for comparison. The error bars in all three graphs represent standard error of the mean. tion in the membrane invagination at this junction (Tidball and Law, 1991). This suggests that dystrophin is involved in the development and/or the maintenance of the MTJ specialization. Since the membrane invagination greatly increases the area of myofibrillar attachment and thus reduces the force load on unit membrane area at the MTJ, its reduction may contribute to the muscle weakness and progressive degeneration in dystrophic muscle.

In this study, we have shown a precise colocalization of dystrophin and talin. Previous studies have also shown the localization of talin and several other peripheral membrane proteins, including vinculin, $58 \mathrm{~K}$ protein and paxillin, at the MTJ (Shear and Bloch, 1985; Tidball et al. 1986; Chen et al. 1990; Turner et al. 1991). This complexity testifies to the intricate nature of the myofibril-membrane interaction. Except for dystrophin and 58K protein (Chen et al. 1990; Sealock et al. 1991), these proteins are also localized at focal contacts of fibroblasts where stress fibers interact with the plasma membrane (Burridge et al. 1988). Although stress fibers can be considered as non-muscle homologues of myofibrils, focal contacts have a much simpler structure than the MTJ. For instance, they do not possess deep membrane invaginations (Chen and Singer, 1982). Thus, dystrophin and the $58 \mathrm{~K}$ protein may impart special properties to the sarcolemma to enable the elaboration of the MTJ specializations. The $58 \mathrm{~K}$ protein, similar to dystrophin, is concentrated at the AChR-rich postsynaptic membrane of Tor pedo and skeletal muscle (Froehner et al. 1987). It appears to form a molecular complex with dystrophin in Torpedo (Butler et al. 1992). Our previous immunocytochemical studies have also demonstrated its localization at the fingerlike structures of the Xenopus MTJ, in an identical pattern to the dystrophin pattern described here (Chen et al. 1990). However, unlike dystrophin, this protein is still present in the $m d x$ mouse, although its association with membrane appears to be decreased (Butler et al. 1992). Thus, it may function in concert with dystrophin at the MTJ. In addition to the proteins described above, recent biochemical studies have identified additional peripheral and integral proteins that can form complexes with dystrophin in skeletal muscle (Ervasti and Campbell, 1991; Butler et al. 1992). It will be interesting to examine whether these proteins are also concentrated at the MTJ.

Our study has shown that dystrophin is not a specialization of the AChR-rich membrane domains at the NMJ (neuromuscular junction) in myotomal muscle fibers. Although previous studies have localized dystrophin to the NMJ of skeletal muscle (Shimizu et al. 1989; Yeadon et al. 1991), recent authors have shown that this protein appears to be associated with the troughs of the folded region of the postsynaptic membrane, not with the crest where AChRs are concentrated (Sealock et al. 1991; Byers et al. 1991). An exception is the Torpedo electric organ postsynaptic membrane, where dystrophin appears to be located in both AChR-rich and AChR-poor domains (Chang et al. 1989; Jasmin et al. 1990; Sealock et al. 1991). Thus, as in the MTJ, dystrophin is also related to membrane invaginations at the NMJ in skeletal muscle. In the Xenopus myotomal muscle fiber, the endplate lacks membrane invaginations (postsynaptic folds). AChRs are concentrated on scalloped membrane patches separated by shallow receptor-free mem- 

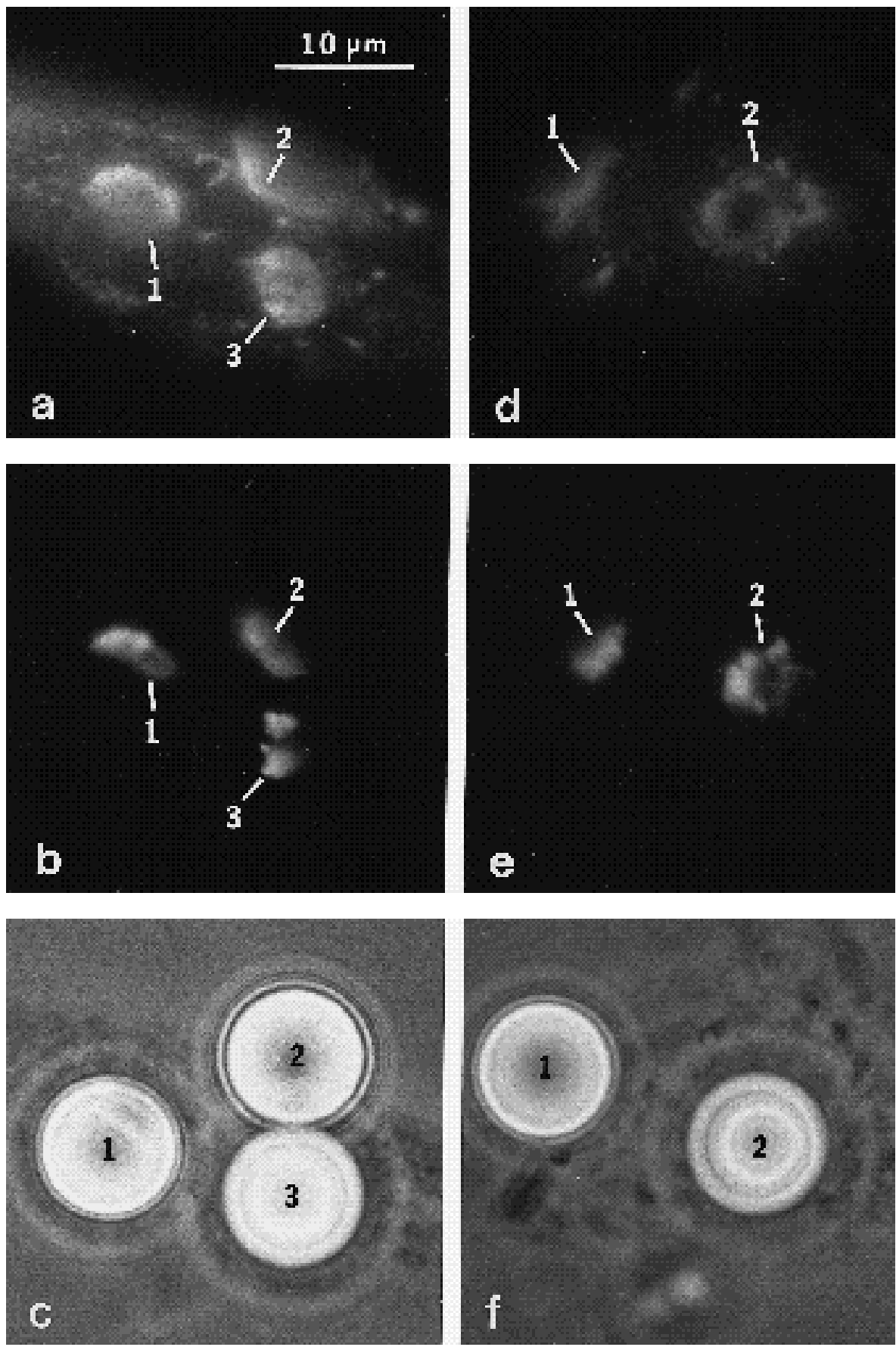

Fig. 7. Localization of dystrophin induced by beads in cultured muscle cells. Dystrophin is present at the bead-muscle contacts (a, mAb 1958 labeling; d, anti-60 $\mathrm{kDa}$ labeling). These sites also show an aggregation of AChRs (b and e), although the patterns of dystrophin and $\mathrm{AChR}$ localization are different. (c and f) show the phase-contrast images of beads.

brane gutters (Kullberg et al. 1977; Rochlin et al. 1989). This NMJ thus has much simpler membrane architecture than NMJs in other skeletal muscle. This simplification may account for the absence of dystrophin at this NMJ. In the $m d x$ muscle, membrane invaginations are reduced in depth, but not totally absent, at the NMJ (Torres and Duchen, 1987; Nagel et al. 1990). Although this muscle is deficient in dystrophin, recent studies have shown the presence of a dystrophin-related protein at the $m d x$ endplate (Fardeau et al. 1990; Ohlendieck et al. 1991; Khurana et al. 1991). This latter protein is also present at the endplate of normal muscle (Ohlendieck et al. 1991; Khurana et al. 1991). These results suggest that the membrane specialization at the NMJ may receive contributions from both dystrophin and its related protein.

\section{Induction of dystrophin localization in cultured muscle cells}

The induction of dystrophin localization by beads in cultured myotomal muscle cells provides a model system for understanding the relationship between this protein and other sarcolemma specializations. Since these cultured muscle cells are the in vitro counterpart of the larval myotomal muscle fibers, our results on the dystrophin localization in vivo can be used to interpret the in vitro data. As our observations in vivo clearly show that dystrophin is 

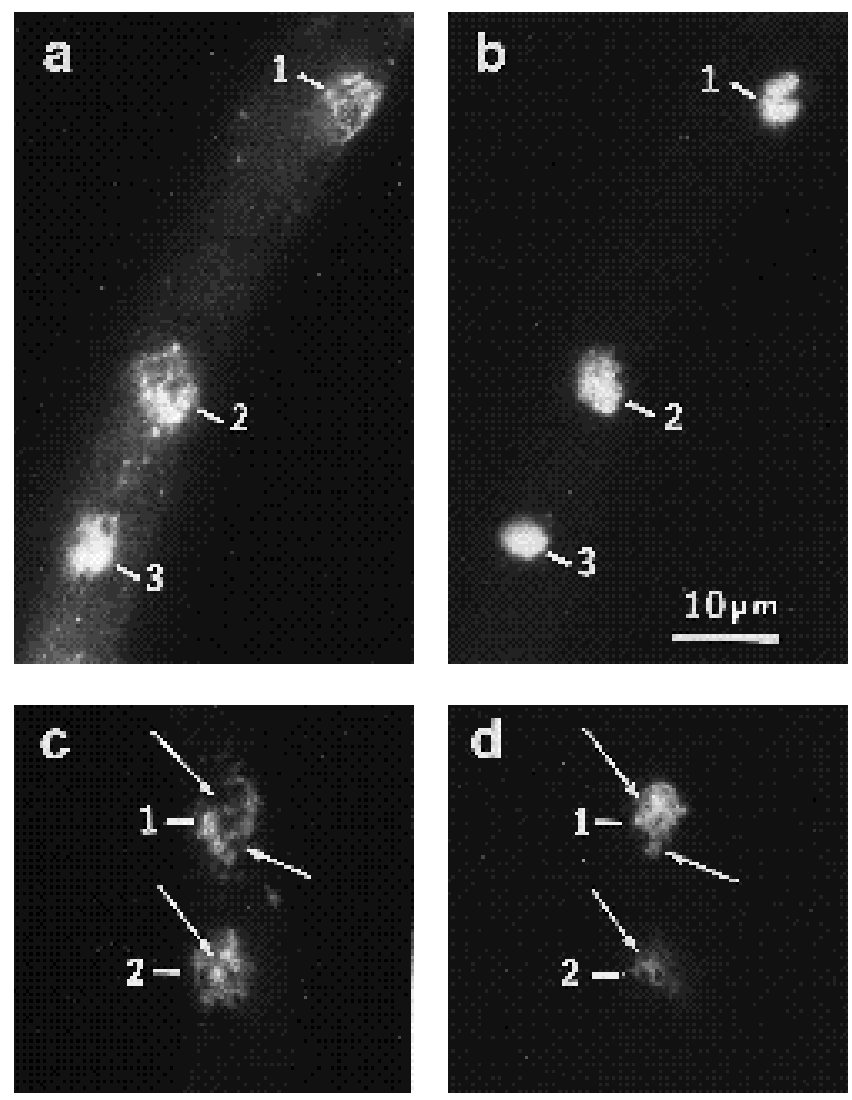

Fig. 8. Comparison of the patterns of dystrophin and AChR localization induced by beads. Left column shows the dystrophin pattern revealed by mAb 1958 labeling. Right column shows AChR clusters. The differences in these two patterns are evident at all the bead-muscle contacts (indicated by numbers) in these two cells. Complementary patterns of these two proteins can be observed in $\mathrm{c}$ and $\mathrm{d}$ at areas indicated by arrows.

associated with the MTJ specialization and not with AChR clusters, we can conclude that the membrane domain where dystrophin is localized at the bead-muscle contact in cultured muscle cells is homologous to the MTJ in vivo. This is consistent with our electron microscopic observation that the sarcolemma in contact with the bead bears a striking resemblance to MTJ. In fact, this bead-induced specialization satisfies all the structural criteria of an MTJ: myofibrils insert into the membrane at the contact; the membrane is undercoated with an electron-dense material at the site of myofibrillar insertion; a basement membrane overlays the cell surface; the membrane is deeply invaginated. In addition, the bead-muscle contact is also the site of a molecular specialization composed of several proteins characteristic of the MTJ, including talin, vinculin, $58 \mathrm{~K}$ protein and dystrophin (Rochlin et al. 1989; Chen et al. 1990). Thus, bead-muscle coculture offers a simple model for studying the biogenesis of the MTJ.

Using membrane invagination as a marker for the development of the MTJ at the bead-muscle contact, we have found that this process is quantitatively closely correlated with dystrophin localization. Our previous studies have shown that other MTJ-related proteins, such as talin and $58 \mathrm{~K}$ protein, become localized at bead-muscle contacts with a much faster time course than dystrophin (Rochlin et al. 1989; Chen et al. 1990). They first become detectable within several hours and are fully expressed within $24 \mathrm{~h}$, much earlier than the full development of the membrane invagination. In contrast, it took 3 to 4 days before dystrophin became detectable at all bead-muscle contacts. This slow time course of the association of dystrophin with the sarcolemma relative to AChR clustering has also been reported by Sealock et al. (1991). This distinct property of dystrophin among known members of MTJ-associated proteins again suggests its important role in the assembly of this specialization.

Our previous studies have shown that the beads are also effective stimuli for the induction of AChR clusters (Peng and Cheng, 1982), which are related to the NMJ specialization in vivo. On the basis of the finding that the pattern of dystrophin localization is in general incongruent with AChR clusters, we can conclude that these clusters are located in areas separated from MTJ-like domains at the bead-muscle contact. Indeed, the segregation of these two membrane domains is obvious in electron micrographs: the AChR domains appear as gentle membrane mounds in the midst or along the MTJ-type membrane invaginations. This study suggests that the stimulus presented by beads is interpreted by the muscle cell as a signal to form both types of specializations. It will be intriguing to find out whether a single signal transduction pathway or two independent ones are involved in the specification of these two types of specialization in this model. In the Xenopus system, it may be possible to suppress the association of dystrophin with the membrane through microinjection of antibodies or antisense oligonucleotides. One could then use this culture model directly to test the role of this protein in MTJ formation.

We are grateful for the generous gifts of antibodies from Drs. Keith Burridge, Stanley Froehner and Eric Hoffman, for the sample of Torpedo postsynaptic membranes from Dr. Robert Sealock, and for recombinant bFGF from Synergen. We also thank Drs. Sealock and Froehner for critical reading of the manuscript. This work was supported by NIH grant NS23583 and the Muscular Dystrophy Association.

\section{References}

Arahata, K., Ishiura, S., Ishiguro, T., Tsukahara, T., Suhara, Y., Eguchi, C., Ishihara, T., Nonaka, I., Ozawa, E. and Sugita, H. (1988). Immunostaining of skeletal and cardiac muscle surface membrane with antibody against Duchenne dystrophy peptide. Nature 333, 361-363.

Bennett, V. (1990). Spectrin-based membrane skeleton: A multipotential adaptor between plasma membrane and cytoplasm. Physiol. Rev. 70, 1029-1066.

Bloch, R. J. and Pumplin, D. W. (1988). Molecular events in synaptogenesis: nerve-muscle adhesion and postsynaptic differentiation. Amer. J. Physiol. 254, C345-C364.

Bozyczko, D., Decker, C., Muschler, J. and Horwitz, A. F. (1989). Integrin on developing and adult skeletal muscle. Exp. Cell Res. 183, 72 91.

Burridge, K. and Connell, L. (1983). A new protein of adhesion plaques and ruffling membranes. J. Cell Biol. 97, 359-367.

Burridge, K., Fath, K., Kelly, T., Nuckolls, G. and Turner, C. (1988). Focal adhesions: transmembrane junctions between the extracellular matrix and the cytoskeleton. Annu. Rev. Cell Biol. 4, 487-525.

Butler, M. H., Douville, K., Murnane, A. A., Kramarcy, N. R., Cohen, J. 
B., Sealock, R. and Froehner, S. C. (1992). Association of the $\mathrm{Mr}$ 58,000 postsynaptic protein of electric tissue with Torpedo dystrophin and the Mr 87,000 postsynaptic protein. J. Biol. Chem. 267, 6213-6218.

Byers, T. J., Husain-Chishti, A., Dubreuil, R. R., Branton, D. and Goldstein, L. S. B. (1989). Sequence similarity of the amino-terminal domain of Drosophila beta spectrin to alpha actinin and dystrophin. $J$. Cell Biol. 109, 1633-1641.

Byers, T. J., Kunkel, L. M. and Watkins, S. C. (1991). The subcellular distribution of dystrophin in mouse skeletal, cardiac, and smooth muscle. J. Cell Biol. 115, 411-421.

Chang, H. W., Bock, E. and Bonilla, E. (1989). Dystrophin in electric organ of Torpedo californica homologous to that in human muscle. $J$. Biol. Chem. 264, 20831-20834.

Chen, Q., Sealock, R. and Peng, H. B. (1990). A protein homologous to the Torpedo postsynaptic $58 \mathrm{~K}$ protein is present at the myotendinous junction. J. Cell Biol. 110, 2061-2071.

Chen, W.-T. and Singer, S. J. (1982). Immunoelectron microscopic studies of the sites of cell-substratum and cell-cell contacts. J. Cell Biol. 95, 205222.

Davison, M. D. and Critchley, D. R. (1988). $\alpha$-Actinins and the DMD protein contain spectrin-like repeats. Cell 52, 159-160.

Engel, A. (1986). Duchenne dystrophy. In Myology, vol. 2 (ed. A.G. Engel and B.Q. Banker), pp. 1185-1240. New York: McGraw-Hill Book Co.

Ervasti, J. M. and Campbell, K. P. (1991). Membrane organization of the dystrophin-glycoprotein complex. Cell 66, 1121-1131.

Fardeau, M., Tome, F. M. S., Collin, H., Augier, N., Pons, F. and Leger, J. (1990). Presence d'une proteine de type dystrophine au niveau de la jonction neuromusculaire dans la dystrophie musculaire de Duchenne et la souris mutante "mdx". C. r. hebd. Séanc. Acad. Sci. Paris, Serie III 311 197-204.

Froehner, S. C. (1991). The submembrane machinery for nicotinic acetylcholine receptor clustering. J. Cell Biol. 114, 1-7.

Froehner, S. C., Murnane, A. A., Tobler, M., Peng, H. B. and Sealock, R. (1987). A postsynaptic $\mathrm{Mr} 58,000(58 \mathrm{~K})$ protein concentrated at acetylcholine receptor-rich sites in Torpedo electroplaques and skeletal muscle. J. Cell Biol. 104, 1633-1646.

Garrett, W.E. Jr and Tidball, J.G. (1988). Myotendinous junctions: structure, function and failure. In Injury and Repair of the Musculoskeletal Soft Tissues (ed. S.L.-Y. Woo and J.A. Buckwalter), pp. 171-207. Park Ridge, Illinois: American Academy of Orthopaedic Surgeons.

Hoffman, E. P., Brown, R. H. Jr and Kunkel, L. M. (1987). Dystrophin: the protein product of the Duchenne muscular dystrophy locus. Cell 51, 919-928.

Hoffman, E. P. and Kunkel, L. M. (1989). Dystrophin abnormalities in Duchenne/Becker muscular dystrophy. Neuron 2, 1019-1029.

Hoffman, E. P., Watkins, S. C., Slayter, H. S. and Kunkel, L. M. (1989). Detection of a specific isoform of alpha-actinin with antisera directed against dystrophin. J. Cell Biol. 108, 503-510.

Jasmin, B. J., Cartaud, A., Ludosky, M. A., Changeux, J. P. and Cartaud, J. (1990). Asymmetric distribution of dystrophin in developing and adult Torpedo marmorata electrocyte: Evidence for its association with the acetylcholine receptor-rich membrane. Proc. Nat. Acad. Sci. USA 87, 3938-3941.

Khurana, T. S., Hoffman, E. P. and Kunkel, L. M. (1990). Identification of a chromosome 6-encoded dystrophin-related protein. J. Biol. Chem. 265, 16717-16720.

Khurana, T. S., Watkins, S. C., Chafey, P., Chelly, J., Tome, F. M. S., Fardeau, M., Kaplan, J.-C. and Kunkel, L. M. (1991). Immunolocalization and developmental expression of dystrophin related protein in skeletal muscle. Neuromusc. Disorders 3, 185-194.

Koenig, M., Monaco, A. P. and Kunkel, L. M. (1988). The complete sequence of dystrophin predicts a rod-shaped cytoskeletal protein. Cell 53, 219-228.

Kramarcy, N. R. and Sealock, R. (1990). Dystrophin as a focal adhesion protein. FEBS Lett. 274, 171-174.

Kreis, T. E. and Birchmeier, W. (1980). Stress fiber sarcomeres of fibroblasts are contractile. Cell 22, 555-561.

Kullberg, R. W., Lentz, T. L. and Cohen, M. W. (1977). Development of the myotomal neuromuscular junction in Xenopus laevis: an electrophysiological and fine-structural study. Develop. Biol. 60, 101129.

Laemmli, U. K. (1970). Clevage of structural proteins during the assembly of the head of bacteriophage T4. Nature 227, 680-685.
Love, D. R., Morris, G. E., Ellis, J. M., Fairbrother, U., Marsden, R. F., Bloomfield, J. F., Edwards, Y. H., Slater, C. P., Parry, D. J. and Davies, K. E. (1991). Tissue distribution of the dystrophin-related gene product and expression in the $m d x$ and $d y$ mouse. Proc. Nat. Acad. Sci. USA 88, 3243-3247.

Luther, P. W. and Bloch, R. J. (1989). Formaldehyde-amine fixatives for immunocytochemistry of cultured Xenopus myocytes. J. Histochem. Cytochem. 37, 75-82.

Mandel, J. L. (1989). The gene and its product. Nature 339, 584-586.

Nagel, A., Lehmann-Horn, F. and Engel, A. G. (1990). Neuromuscular transmission in the $m d x$ mouse. Muscle Nerve 13, 742-749.

Nakao, T. (1976). Some observations on the fine structure of the myotendinous junction in myotomal muscles of the tadpole tail. Cell Tiss. Res. 166, 241-254.

Ohlendieck, K., Ervasti, J. M., Matsumura, K., Kahl, S. D., Leveille, C. J. and Campbell, K. P. (1991). Dystrophin-related protein is localized to neuromuscular junctions of adult skeletal muscle. Neuron 7, 499-508.

Peng, H.B., Baker, L.P. and Chen, Q. (1991a). Tissue culture of Xenopus neurons and muscle cells as a model for studying synaptic induction. In Xenopus laevis: Practical Uses in Cell and Molecular Biology. Methods in Cell Biology, vol. 36 (ed. B.K. Kay and H.B. Peng), pp. 511-526. San Diego: Academic Press.

Peng, H. B., Baker, L. P. and Chen, Q. (1991b). Induction of synaptic development in cultured muscle cells by basic fibroblast growth factor. Neuron 6, 237-246.

Peng, H. B. and Cheng, P.-C. (1982). Formation of postsynaptic specializations induced by latex beads in cultured muscle cells. $J$. Neurosci. 2, 1760-1774.

Peng, H. B. and Phelan, K. A. (1984). Early cytoplasmic specialization at the presumptive acetylcholine receptor cluster: a meshwork of thin filaments. J. Cell Biol. 99, 344-349.

Porter, S. and Froehner, S. C. (1983). Characterization of the Mr 43,000 proteins associated with acetylcholine receptor-rich membranes. J. Biol. Chem. 258, 10034-10040.

Rochlin, M. W., Chen, Q., Tobler, M., Turner, C. E., Burridge, K. and Peng, H. B. (1989). The relationship between talin and acetylcholine receptor clusters in Xenopus muscle cells. J. Cell Sci. 92, 461-472.

Samitt, C. E. and Bonilla, E. (1990). Immunocytocemical study of dystrophin at the myotendinous junction. Muscle Nerve 13, 493-500.

Sealock, R., Butler, M. H., Kramarcy, N. R., Gao, K.-X., Murnane, A. A., Douville, K. and Froehner, S. C. (1991). Localization of dystrophin relative to acetylcholine receptor domains in electric tissue and adult and cultured skeletal muscle. J. Cell Biol. 113, 1133-1144.

Sealock, R. and Kavookjian, A. (1980). Postsynaptic distribution of acetylcholine receptors in electroplax of the Torpedine ray, Narcine brasiliensis. Brain Res. 190, 81-93.

Shear, C. R. and Bloch, R. J. (1985). Vinculin in subsarcolemmal densities in chicken skeletal muscle: localization and relationship to intracellular and extracellular structures. J. Cell Biol. 101, 240-256.

Shimizu, T., Matsumura, K., Sunada, Y. and Mannen, T. (1989). Dense immunostainings on both neuromuscular and myotendon junctions with an anti-dystrophin monoclonal antibody. Biomed. Res. 10, 405-409.

Swasdison, S. and Mayne, R. (1989). Location of the integrin complex and extracellular matrix molecules at the chicken myotendinous junction. Cell Tiss. Res. 257, 537-543.

Swasdison, S. and Mayne, R. (1991). In vitro attachment of skeletal muscle fibers to a collagen gel duplicates the structure of the myotendinous junction. Exp. Cell Res. 193, 227-231.

Thi Man, N., Ellis, J. M., Love, D. R., Davies, K. E., Gatter, K. C., Dickson, G. and Morris, G. E. (1991). Localization of the DMDL geneencoded dystrophin-related protein using a panel of nineteen monoclonal antibodies: Presence at neuromuscular junctions, in the sarcolemma of dystrophic skeletal muscle, in vascular and other smooth muscles, and in proliferating brain cell lines. J. Cell Biol. 115, 1695-1700.

Tidball, J. G. and Daniel, T. L. (1986). Myotendinous junctions of tonic muscle cells: structure and loading. Cell Tiss. Res. 245, 315-322.

Tidball, J. G. and Law, D. J. (1991). Dystrophin is required for normal thin filament-membrane associations at myotendinous junctions. Amer. J. Path. 138, 17-21.

Tidball, J. G. and Lin, C. (1989). Structural changes at the myogenic cell surface during the formation of myotendinous junctions. Cell Tiss. Res. 257, 77-84.

Tidball, J. G., O'Halloran, T. and Burridge, K. (1986). Talin at myotendinous junctions. J. Cell Biol. 103, 1465-1472. 
Torres, L. F. B. and Duchen, L. W. (1987). The mutant $m d x$ : inherited myopathy in the mouse. Brain 110, 269-299.

Towbin, H., Staehelin, T. and Gordon, J. (1979). Electrophoretic transfer of proteins from polyacrylamide gels to nitrocellulose sheets: procedure and some applications. Proc. Nat. Acad. Sci. USA 76, 4350-4354.

Trotter, J. A. (1985). A morphometric analysis of the muscle-tendon junction. Anat. Rec. 213, 26-32.

Trotter, J. A., Corbett, K. and Avner, B. P. (1981). Structure and function of the murine muscle-tendon junction. Anat. Rec. 201, 293-302.

Turner, C. E., Kramarcy, N., Sealock, R. and Burridge, K. (1991). Localization of paxillin, a focal adhesion protein, to smooth muscle dense plaques, and the myotendinous and neuromuscular junctions of skeletal muscle. Exp. Cell Res. 192, 651-655.
Watkins, S. C., Hoffman, E. P., Slayter, H. S. and Kunkel, L. M. (1988). Immunoelectron microscopic localization of dystrophin in myofibres. Nature 333, 863-866.

Yeadon, J. E., Lin, H., Dyer, S. M. and Burden, S. J. (1991). Dystrophin is a component of the subsynaptic membrane. J. Cell Biol. 115, 10691076.

Zubrzycka-Gaarn, E. E., Bulman, D. E., Karpati, G., Burghes, A. H. M., Belfall, B., Klamut, H. J., Talbot, J., Hodges, R. S., Ray, P. N. and Worton, R. G. (1988). The Duchenne muscular dystrophy gene product is localized in sarcolemma of human skeletal muscle. Nature $\mathbf{3 3 3}, 466-$ 469.

(Received 13 May 1992 - Accepted 13 July 1992) 